\title{
Teatro do oprimido e Terapia Ocupacional: uma proposta de intervençáo com jovens em situaçáo de vulnerabilidade social ${ }^{1}$
}

\author{
Izabela Alves ${ }^{\mathrm{a}}$, Daniela Tavares Gontijo ${ }^{\mathrm{b}}$, Heliana Castro Alves ${ }^{\mathrm{c}}$
}

\begin{abstract}
${ }^{a}$ Terapeuta ocupacional, Universidade Federal do Triângulo Mineiro - UFTM, Uberaba, MG, Brasil 'Professora Doutora do Curso de Terapia Ocupacional e Professora colaboradora no Programa de Pós-graduação em Saúde da Criança e do Adolescente da Universidade Federal de Pernambuco - UFPE, Pesquisadora do Núcleo de Estudos e Pesquisas em Vulnerabilidade e Saúde na Infância e Adolescência - NEPVIAS - UFPE, Recife, PE

'Professora. Mestre do Curso de Terapia Ocupacional, Universidade Federal do Triângulo Mineiro - UFTM,

Pesquisadora do Núcleo de Estudos e Pesquisas em Vulnerabilidade e Saúde na

Infância e Adolescência - Nepvias-UFTM, Uberaba, MG, Brasil
\end{abstract}

\begin{abstract}
Resumo: Uma das questões que desafiam as políticas de desenvolvimento social na América Latina é a juventude. Esta, quando em situação de vulnerabilidade social, corre risco de perder perspectivas de futuro, não possuindo condições mínimas que garantam sua participação ativa no processo de conquista da cidadania. Nesse sentido, faz-se importante o desenvolvimento de ações que possibilitem a minimização do impacto do processo de vulnerabilização em seus contextos de vida. O objetivo deste artigo foi descrever e analisar a utilização do teatro como recurso terapêutico ocupacional junto a jovens em situação de vulnerabilidade social no processo de conscientização e protagonismo juvenil. Realizou-se um estudo de caso com abordagem qualitativa, em uma instituição filantrópica do interior de Minas Gerais. Foram realizados 10 encontros utilizando atividades teatrais propostas por Augusto Boal, uma apresentação teatral para a comunidade, usando a técnica do teatro-fórum, e grupo focal. A coleta de dados ocorreu a partir de filmagens e elaboração de diários de bordo, analisados a partir da análise de conteúdo. Foram elaboradas três categorias temáticas: o teatro como instrumento de expressão das condições de vulnerabilidade dos jovens; o teatro e o microcosmo social do grupo e da família; e teatro-fórum e elaboração de estratégias de enfrentamento. Ao longo do processo, a técnica do teatro do oprimido possibilitou o desenvolvimento de uma reflexão crítica dos jovens acerca dos problemas vivenciados, instrumentalizando-os para a promoção de um diálogo com a comunidade e a família. A comunidade percebeu o papel social do teatro, refletindo sobre os problemas vivenciados pela juventude.
\end{abstract}

Palavras-chave: Terapia Ocupacional, Vulnerabilidade Social, Adolescente, Arte, Terapia pela Arte.

\section{Theater of the oppressed and Occupational Therapy: a proposed action with youth in social vulnerability}

\begin{abstract}
Youth is one of the challenging issues to social development policies in Latin America. When socially vulnerable, this age group is at risk of losing future prospects in case minimum conditions are not ensured for active participation in the process of gaining citizenship. In this sense, it is important to develop actions to enable a reduction of the vulnerability process impacts in their daily lives. In this study, we aimed to describe and analyze the use of drama as a therapeutic resource with young people in occupational social vulnerability in the process of awareness and youth participation. To this end, we carried out a case study with qualitative approach in a philanthropic institution in the state of Minas Gerais. Ten meetings were conducted using drama the activities proposed by Augusto Boal, a theatrical presentation to the community using the technique of the theater-forum
\end{abstract}

Autor para correspondência: Heliana Castro Alves, Curso de Terapia Ocupacional, Universidade Federal do Triângulo Mineiro, Av. Getúlio Guaritá, s/n, $3^{\circ}$ piso, CEP 38025-440, Uberaba, MG, Brasil, e-mail: helianasolar@gmail.com

Recebido em 17/8/2011; $1^{\text {a }}$ Revisão em 15/2/2012; $2^{\text {a }}$ Revisão em 23/7/2012; Aceito em 8/10/2012 
and focus groups. Data collection occurred through filming and the production of journals analyzed by Content Analysis. We developed three thematic categories: drama as an instrument of expression of the vulnerability conditions of young people; drama and social microcosm of the group and the family; and Theatre Forum and the development of coping strategies. Throughout the process, the technique of the theater of the oppressed enabled the critical thinking development of young people regarding the problems experienced, which helped to promote a dialogue with the community and the family. The community realized the social role of theater, reflecting on the problems experienced by youth.

Keywords: Occupational Therapy, Social Vulnerability, Adolescent, Art, Art Therapy.

\section{Introdução}

O teatro do oprimido é uma técnica criada por Augusto Boal (1931-2009) que apresenta aspectos pedagógicos, sociais, culturais, políticos e terapêuticos (TEIXEIRA, 2007). No âmbito da história do teatro brasileiro a técnica é identificada como uma das representantes do teatro-político, inserindo-se no debate sobre a realidade social a partir de um aparato político-estético que se baseia na criação dinâmica de peças teatrais. Surgindo no contexto político-social da ditadura militar, o teatro do oprimido refuta a ideia da arte isolada da vida e se desdobrou da gestão de práticas de resistência democrática que compôs o cenário das lutas sociais do país no período da repressão política (TEIXEIRA, 2007).

Considerado um método de intervenção social e política, a prática teatral revolucionária tem por princípio a luta pela libertação do sistema de opressáo: libertando-se o espectador da sua condição passiva de observar a cena, ele poderá libertar-se de outras opressóes que compóem o cenário da sua realidade social (TEIXEIRA, 2007).

Boal (2009) propõe algumas metodologias para o teatro do oprimido, sendo o teatro-fórum a mais conhecida e praticada no mundo. Nessa técnica, que utiliza diversos recursos, os espectadores são convidados a entrar em cena e substituírem os atores, ocupando o lugar destes na cena. Assim, os espectadores revelam seus pensamentos, desejos e estratégias, sugerindo à comunidade a qual pertencem

[...] um leque de alternativas/estratégias possíveis por eles próprios inventadas: o teatro deve ser um ensaio para a ação na vida real, e não um fim em si mesmo. (BOAL, 2009, p. 19).

Para Boal (2002), o teatro permite ao homem observar a si mesmo em ação, adquirindo o autoconhecimento que lhe permite ser sujeito (o que observa) de um outro sujeito (o que age) e lhe permite imaginar e interpretar possibilidades de uma ação e outras alternativas.
Desta forma, Boal (2002, p. 29) define o teatro do oprimido como

[...] um sistema de exercícios físicos, jogos estéticos, técnicas de imagem e improvisaçóes especiais, que tem por objetivo resgatar, desenvolver e redimensionar essa vocação humana, tornando a atividade teatral um instrumento eficaz na compreensão e na busca de soluçóes para problemas sociais e interpessoais.

Teixeira (2007) relaciona a pedagogia do oprimido, de Paulo Freire, com a técnica político-estética de Augusto Boal afirmando que ambas trabalham com o sistema opressor e oprimido, sendo que Boal incorpora a metodologia de Freire, assumindo a visão de que as pessoas devem construir seu conhecimento com liberdade, autonomia numa relação dialógica com o outro e o meio (TEIXEIRA, 2007).

Para Dall'Orto (2008) o teatro do oprimido, inspirado na filosofia marxista, se preocupa com as relaçóes sociais de uma população oprimida, alvo de um sistema que gera desigualdade social numa sociedade de classes. Na América Latina, os temas do teatro do oprimido giram em torno das condiçóes de vida sub-humanas que envolvem os desníveis sociais e temas políticos emergentes e coletivos. São utilizadas técnicas no intuito de trabalhar as situaçóes de opressão e discutir as problemáticas do cotidiano, para a promoção de uma transformação social.

De acordo com Abramovay et al. (2002), a juventude se caracteriza como uma das questôes que desafiam as políticas de desenvolvimento social na América Latina. Concebida pela sua condição social, a juventude é parametrizada por uma faixa etária que no Brasil congrega cidadãos com a idade compreendida entre 15 e 29 anos, no entanto essa faixa etária constitui apenas um parâmetro social para o reconhecimento político da fase da juventude 
(BRASIL, 2006). Segundo a Organização das Naçôes Unidas (2005), há 1,2 bilhão de jovens no mundo, sendo que cerca de 209 milhóes destes são de classes socioeconômicas mais baixas. Para Abramovay et al. (2002), essa população tem sofrido limitaçóes nas suas perspectivas de futuro em virtude do aumento da violência e da pobreza e de restriçóes nas oportunidades de trabalho, com consequências diretas nas possibilidades de obtenção de condiçôes mínimas que garantam sua participação ativa no processo de conquista da cidadania. Dessa forma, a autora define a vulnerabilidade social como o

[...] resultado negativo da relaçáo entre a disponibilidade dos recursos materiais ou simbólicos dos atores, sejam eles indivíduos ou grupos, e o acesso à estrutura de oportunidades sociais, econômicas, culturais que provêm do Estado, do mercado e da sociedade. Esse resultado se traduz em debilidades ou desvantagens para o desempenho e mobilidade social dos atores. (ABRAMOVAY et al., 2002, p. 30).

Sabe-se que a escassez de recursos por parte de um grupo social caracteriza o modo de produção capitalista instrumentalizado pela concentração de renda e a desigualdade na distribuição de renda numa sociedade de classes, polarizando o poder econômico a um grupo dominante. A violência estrutural, fruto sócio-histórico, produz o binômio opressor-oprimido descrito por Paulo Freire (1987), no qual a população de classes mais baixas é oprimida pelas classes mais altas privilegiadas ou, ainda, em uma sociedade adultocêntrica, em que crianças e jovens são oprimidos por adultos.

Para Paulo Freire (1987), a práxis/reflexão pressupóe a açáo transformadora do homem sobre o mundo e constitui indispensável elemento para a superação da relação oprimido-opressor. Ao considerarmos o público juvenil é necessário enfatizar sua desejável participação como protagonistas de seu processo de desenvolvimento, empoderando-os como sujeitos sócio-históricos. Nesse sentido, Costa (2001) aponta o conceito de protagonismo juvenil para designar a participação de adolescentes no enfrentamento de situaçóes reais na escola, na comunidade e na vida social mais ampla, extrapolando os âmbitos de seus interesses individuais e familiares a partir de adesão a campanhas, movimentos e outras formas de mobilizaçáo que podem vir a transcender os limites de seu entorno sócio-comunitário.

Abramovay et al. (2002) alertam que tais açôes são importantes, já que concretizam as potencialidades juvenis e permitem que eles colaborem com a problematizaçáo de seu cotidiano, captando e disseminando suas expressóes. Considera-se, porém, que a realidade só pode ser modificada quando o sujeito percebe que ela é modificável e que pode fazê-lo a partir de um necessário processo de conscientização, preparando o indivíduo "[...] para um juízo crítico das alternativas propostas pela elite, e dar a possibilidade de escolher o próprio caminho." (FREIRE, 1980, p. 20).

No campo das políticas públicas, a trajetória pelo avanço das conquistas sociais é historicamente recente. Desde a promulgaçáo do Estatuto da Criança e do Adolescente, em 1990, nas lutas sociais em torno dos direitos sociais do segmento jovem observa-se um consenso em torno da necessidade de implementação de políticas públicas destinadas à juventude, considerada como fase de vida marcada por uma certa instabilidade associada a determinados "problemas sociais" (SPOSITO; CARRANO, 2003). Percebe-se, porém, alguns avanços significativos: em 2004 o governo federal criou o Grupo Interministerial da Juventude, coordenado pela Secretaria Geral da Presidência da República, com 19 ministérios e secretarias que recomendou a criaçáo de um Conselho Nacional de Juventude e de uma Secretaria Nacional de Juventude com o papel de integrar programas e açóes do governo federal sendo referência da própria população jovem no governo. Esse conselho, em 2006, criou a Política Nacional de Juventude contendo diretrizes e perspectivas para a promoção de direitos universais e específicos desse segmento (BRASIL, 2006).

Nesse sentido, a terapia ocupacional no campo social pode contribuir significativamente já que atua justamente com uma

[...] população excluída ao acesso dos bens sociais e cuja problemática se manifesta pelo agravamento das condiçóes de vida a que está submetida. (GALHEIGO, 2003, p. 34).

De acordo com a autora, neste âmbito o terapeuta ocupacional deve favorecer a organização do coletivo possibilitando a construçáo da cidadania plena.

A Associação Americana de Terapia Ocupacional (AMERICAN..., 2008), ao lado da noçáo de justiça social, define justiça ocupacional como a garantia da oportunidade de participação nas ocupaçóes escolhidas pelos indivíduos, ocupaçóes estas que tenham propósito e significado em suas vidas. Parte-se do princípio de que o indivíduo deve se envolver em ocupaçóes e atividades que são importantes ou necessárias a ele, sejam em casa, na escola, no trabalho e/ou na vida comunitária. Carleto, Alves e Gontijo (2010) afirmam que a 
trajetória de vida de jovens marcados pela vivência das situaçôes de vulnerabilidade social pode influenciar as oportunidades que tiveram, e eles têm de se envolver em ocupaçóes que sejam significativas, caracterizando quadros de privação ocupacional em cenários de injustiça ocupacional.

Nos cenários de injustiça ocupacional são necessárias açóes empoderadoras que envolvam intervençôes direcionadas ao público e ao ambiente, principalmente ações de fortalecimento da rede social de suporte. De acordo com Barros, Lopes e Galheigo (2007), as atividades devem constituir-se instrumentos de emancipação alimentados pela dimensão sociopolítica, cultural e afetiva de pessoas, de grupos e de comunidades.

Entre as atividades que podem ser utilizadas pelo terapeuta ocupacional com jovens em situação de vulnerabilidades social, o teatro do oprimido pode ser vislumbrado como técnica eficaz ao considerarmos seu cunho reflexivo, que possibilita o acesso às atividades significativas em diferentes áreas de desempenho ocupacional como lazer, educação e participação social. Teixeira (2011), a partir de uma revisão de literatura, apresenta interfaces entre o teatro do oprimido e a prática do terapeuta ocupacional, buscando intersecçóes entre a arte e a clínica e o benefício do teatro no processo terapêutico. Dessa forma, considerando os estímulos proporcionados pela atividade teatral, esse recurso possibilita imbricações com os objetivos terapêuticos a partir da vivência do ato criativo e o encontro com o outro.

Como observam Côrtes, Gontijo e Alves (2011), as atividades expressivas, norteadas por ação e movimento, tornam-se significativas para o trabalho com jovens. Coutinho (2006, p. 117), ao realizar o relato da experiência de projetos com grupos de teatros em comunidades pobres no Rio de Janeiro, enfatiza o crescente interesse por parte de crianças e jovens da comunidade, em açóes nas quais as mobilidades artísticas aparecem como

[...] ferramentas capazes de conter o caos social e a violência, oferecendo a crianças e adolescentes alternativas culturais emocionantes, com as quais possam identificar-se e transformar em opção de vida.

Nesse sentido, a valorização dos elementos próprios da comunidade e de sua cultura e as formas de expressão foram os fatores que determinaram a adesão dos jovens e da comunidade (COUTINHO, 2006).

Nesse sentido, a arte, o esporte, a educação e a cultura representam elementos estratégicos para o enfrentamento e combate à violência possibilitando um incentivo aos jovens para afastarem-se de situaçóes de perigo, sem lhes negar meios de expressão e descarga dos sentimentos de indignação, protesto e afirmação positiva de suas identidades (CASTRO et al., 2001). Durante a atividade dramática o jovem poderá encontrar e dramatizar outras possibilidades de enfrentamento de seus dramas sociais, numa perspectiva, como aponta Dall'Orto (2008), de preparação do futuro através de questôes que oprimem a populaçáo no presente, e não apenas a passiva reflexão sobre o passado.

Considerando esses aspectos, esta pesquisa tem como objetivo descrever e analisar a utilizaçáo do teatro como recurso terapêutico ocupacional junto a jovens em situação de vulnerabilidade social no processo de conscientização e protagonismo juvenil.

Espera-se que este artigo contribua com subsídios para o desenvolvimento de estratégias de intervençóes com a população jovem, especialmente em relação à atuação terapêutica ocupacional no campo social, fortalecendo a produção de conhecimento na área.

\section{Procedimentos metodológicos}

Este trabalho caracteriza-se como um estudo de caso, com abordagem qualitativa, realizado em uma instituição de caráter filantrópico localizada numa comunidade de moradores em situação de vulnerabilidade social em um município do interior de Minas Gerais. A instituição em questão possui colaboração técnica com a Universidade Federal do Triângulo Mineiro para realização dos estágios em terapia ocupacional, apresentando a demanda específica para se trabalhar com o público em questão, em virtude da exposição dos jovens a um bairro que apresenta condiçóes sociais marcadas pela desigualdade que gera problemáticas como violência, drogas e rede de prostituição.

Participaram da pesquisa 7 homens e 4 mulheres, com faixa etária, em média de 15 anos, que se inscreveram na oficina de teatro. A atividade em questão mostrou-se significativa para este público que demandava ao setor de terapia ocupacional por oficinas que envolvessem expressão corporal.

Foram realizadas dez intervençóes terapêuticoocupacionais com o público-alvo utilizando como principal recurso atividades teatrais com embasamento de Augusto Boal (2009). Os adolescentes, junto com seus pais, foram informados e assinaram o Termo de Consentimento Livre Esclarecido.

Como finalização das oficinas, a comunidade foi convidada a assistir à peça de teatro do grupo, a partir da técnica de teatro-fórum (BOAL, 2009) que colocou em debate os temas gerados no decorrer 
das oficinas, subsidiando, dessa forma, a construção coletiva de estratégias de enfrentamento aos problemas abordados. Os espectadores da comunidade foram informados sobre o caráter da pesquisa, aceitando a participação durante o teatro-fórum.

Enquanto metodologia de intervençáo utilizaram-se fundamentos práticos das técnicas do teatro do oprimido de Augusto Boal (2002, 2008, 2009), sendo que a aproximaçáo com o público durante as oficinas e a forma de condução dos debates transcorridos das experiências teatrais e jogos dramáticos também se alinharam à proposta de Paulo Freire (1980, 1987, 1996). Para tanto, elaboraram-se, durante as oficinas, temas geradores que se aproximavam da realidade dos jovens participantes, a partir das situaçóes de conflito relatadas espontaneamente durante os jogos teatrais, juntamente com as possibilidades de enfrentamento das situaçóes de vulnerabilidade social construídas no coletivo do grupo e da comunidade durante a aplicação da técnica.

Para coleta dos dados foram utilizadas as filmagens das intervençôes, anotaçóes em diário de campo e um grupo focal com os jovens ao final das intervençôes.

A análise de dados ocorreu a partir de análise de conteúdo temática (MINAYO; DESLANDES; GOMES, 2007).

Dessa maneira, foi possível identificar e sistematizar os temas mais frequentes, possibilitando uma discussão sobre os dados obtidos, de acordo com o objetivo proposto. A partir da análise dos dados, foi possível delinear três categorias temáticas que serão discutidas: o teatro como instrumento de expressão das condiçôes de vulnerabilidade dos jovens; o teatro e o microcosmo social do grupo e da família; e o teatro-fórum e a elaboração de estratégias de enfrentamento.

A pesquisa foi aprovada pelo Comitê de Ética em Pesquisa com Seres Humanos da UFTM pelo protocolo n. 1570.

\section{Resultados e discussão}

O Teatro do Oprimido jamais foi um teatro equidistante que se recuse a tomar partido - é o teatro de luta! É o teatro DOS oprimidos, PARA os oprimidos, SOBRE os oprimidos e PELOS oprimidos, sejam eles operários, camponeses, desempregados, mulheres, negros, jovens ou velhos, portadores de deficiência física ou mental, enfim, todos aqueles a quem se impóe o silêncio e de quem se retira o direito à existência plena. (BOAL, 2009, p. 30).

\subsection{Teatro: expressão das condições de vulnerabilidade de jovens}

$\mathrm{Na}$ primeira categoria, o teatro como instrumento de expressão das condiçóes de vulnerabilidade dos jovens, apresentamos os relatos coletados através dos jogos teatrais e das dramatizaçóes que expressam o contexto de vida dos jovens participantes e suas condiçôes de vulnerabilidade social. Os principais temas gerados espontaneamente durante as oficinas foram: droga, violência, relaçóes com a polícia, sexualidade e relacionamentos interpessoais.

O primeiro aspecto abordado se relaciona com a questão da drogadição nas vivências cotidianas desses jovens. A partir das dramatizaçóes de cenas vividas e de jogos teatrais como dramaturgia simultânea, desafio, contar sua história, os participantes realizaram relatos que permitiram identificar a facilidade de acesso a entorpecentes, assim como sua utilização por integrantes da própria família e do bairro.

Se você passar no meu bairro ali de madrugada, "cê" fica com o nariz até ardendo por causa do cheiro, forte demais (J.8).

Segundo Schenker e Minayo (2005, p. 710),

[...] a disponibilidade e a presença de drogas na comunidade de convivência têm sido vistas como facilitadoras do uso de drogas por adolescentes, uma vez que o excesso de oferta naturaliza o acesso.

Nesse sentido, as autoras apontam para uma sintonia de fatores de risco, quando a disponibilidade cruza com a desorganização social e outros. Desse modo, os fatores de risco não devem ser pensados isoladamente, uma vez que, geralmente, para levar ao uso da droga, eles se relacionam.

A realização de atividades expressivas e jogos teatrais, como Jogo da Verdade, possibilitou discussóes no grupo sobre os temas. Um participante revelou já ter feito uso de droga, suscitando a discussão sobre os motivos que os levam a procurar a droga, como pode ser observado abaixo.

É, as pessoas "oferece", mas ele só fuma se ele quiser, depende das amizades. Se eu "tiver" fumando maconha e chegar nele, "nóis tem" amizade, se eu chegar nele e falar "quer fumar um brown aí irmão?”, ele vai e fuma (J.11).

Alguns participantes acreditam que as amizades podem determinar a entrada do jovem no mundo das drogas. Outros, no entanto, refutam esse 
posicionamento e destacam a importância do estudo como fator de proteção:

Mas assim, as amizades não "é" tanto, por que assim, se você não "querer", você não pega. Agora, se você fala assim "ah, deixa eu experimentar, deixa eu vê se é "bão" aí você já vai querer e vai querendo. [...] eu estudo, eu aprendo... eu vou "na" minha cabeça, eu não vou "na" cabeça de colega nenhum... (J.9).

De acordo com Schenker e Minayo (2005, p. 708), a adolescência constitui um período crucial no ciclo vital para o início do uso de drogas, seja como mera experimentação seja como consumo ocasional, indevido ou abusivo. Nesse sentido, as autoras apontam que, comumente, o jovem busca na droga novas sensaçóes, prazer, compartilhamento grupal, independência em relação à família, não dimensionando o perigo a que se expóe. Quanto à influência dos amigos no uso de drogas, Schenker e Minayo (2005) abordam que realmente há influência dos grupos, entretanto não se deve supervalorizar essa influência.

Estudos indicam, por outro lado, que diversas características familiares também estão associadas ao uso de drogas pelos adolescentes, entre elas, relacionamentos conflituosos com pai e mãe, maustratos e separação dos pais (TAVARES; BÉRIA; LIMA, 2004).

Tem muitos "pobrema" em casa, "pobrema" na rua. Aí pode ser que ele "quer" superar isso tudo. Briga de mãe, de pai, de irmão enche seu saco, muitas coisas [...] ele quer um pouco de paz na vida (J.9).

Schenker e Minayo (2005) apontam que adolescentes cujos pais fazem consumo de drogas possuem maior risco de se tornarem usuários, uma vez que o comportamento dos pais serve de modelo. A fala de um dos participantes revela esse fator de risco: "Eu não tenho vergonha de falar, meu pai fumava... um custo, um custo 'pra' ele sai disso!” (J.9) Entretanto, os autores alertam que a relação não é causal e que a maior influência nessa relação é da atitude permissiva dos pais. Esses autores pontuam que algumas combinaçóes de comportamentos parentais são de risco para o uso de droga pelo jovem. Dentre eles vê-se principalmente a ausência de vínculo entre pais e filhos, práticas disciplinares inconsistentes, permissividade excessiva, dificuldade no estabelecimento de limites, educação autoritária, pouca afetividade e conflitos familiares sem desfecho. Percebe-se então que quando as relaçôes familiares estão fragilizadas o jovem está em maiores condiçóes de risco de buscar a droga (SCHENKER; MINAYO, 2005).

$\mathrm{O}$ processo de condução das oficinas salientou o mote da violência no contexto familiar, que compôs os debates dos jovens durante e após as dramatizaçôes, como é destacado abaixo.

Meu pai não me bate não, ele me espanca (J.2). O meu padrasto bate na minha mãe. Uma vez ele ia bater nela, aí eu joguei o botijão, aí peguei o revólver e botei na cara dele assim, só que eu não tive coragem de atirar (J.11).

Segundo Lopes et al. (2008), a violência tem se tornado banalizada entre adolescentes e jovens, principalmente aqueles de classe desfavorecida. Para as autoras isso se deve ao alto número de situaçóes corriqueiras de violência no cotidiano desses adolescentes e jovens, apontando para a existência de um imaginário social que expressa valores sociais pautados no castigo e na puniçáo como meios de correçâo de comportamentos indesejáveis. As autoras afirmam que esse público vivencia cotidianamente práticas de violência, o que acaba gerando um estigma para a população, que passa a ser diretamente relacionada com periculosidade.

Outro tema relacionado às condiçóes de vulnerabilidade foi a transgressóes de regras sociais e as relações de poder. Durante as intervenções foram observados alguns relatos e dramatizações que expressavam a transgressão de regras, principalmente relacionada ao roubo, como pode ser identificado na fala de um participante em conflito com a lei que cumpria medidas socioeducativas.

\begin{abstract}
Sabe por que que tem que roubar "fessora"? Porque eles são "rico" e pensam que pode mais que a gente pobre, eles "zoa" da cara da gente. Mesmo se a gente tem dinheiro, a gente entra no mercado ali, assim, com uma bermuda, uma camisa, um chinelo. A gente entra e eles vão pensar que a gente vai pedir ou roubar, eles vêm discriminando a gente (J.11).
\end{abstract}

O participante em questão relata um assalto armado que cometeu para realizar o roubo de um celular. Cavalcante, Starling e Eisenberg (2004, p. 54) afirmam que meninos pobres nas ruas das cidades brasileiras são sujeitos socialmente invisíveis e que as elites "passam por eles como se eles não existissem". A invisibilidade social, ao somar-se à falta de recursos, própria de um sistema de desigualdade naturalizada na violência estrutural do sistema, seduz o jovem ao porte de armas. A arma, por sua vez, sendo instrumento de poder, o torna visível, passando a ser notado pela vítima a partir da imposição do 
medo. Essa atitude reforça o estigma social voltado para a periculosidade e expóe o jovem ainda mais ao ciclo de exclusão social.

A insatisfação das necessidades frequentemente criadas numa sociedade de consumo junto à escassez de recursos provindos da desigualdade social, para Galheigo (2003), contribuem para a construção do sujeito excluído. Nesse sentido, a violência assume lugar privilegiado no discurso e mediaçáo dos conflitos, constituindo também uma das poucas oportunidades do exercício do poder e da autodeterminação dos que se sentem excluídos (GALHEIGO, 2003).

Nesse sentido, o discurso do participante revela que o comportamento de transgressão do roubo, juntamente com o fator da restrição de bens simbólicos, é reforçado socialmente, como se necessitasse corresponder ao estigma de periculosidade social que lhe foi imposto e ao mesmo tempo gerado pelos seus próprios atos, dificultando a mudança de comportamento. Evidencia-se nesse discurso um conflito entre a assunção das responsabilidades pelos próprios atos e a compreensão da malha social que o aprisiona numa imagem da qual não consegue se desvencilhar facilmente. A intensa disparidade social provinda do modelo socioeconômico instalado no país leva, como ressalta Moreira e Queiroz (2005), muitos jovens a escolherem o mundo da violência como principal referência identitária.

Também se fez presente durante as "dramatizaçôes de histórias de vida" os conflitos inerentes às relaçôes de poder, sobretudo com a polícia militar, como se pode verificar abaixo.

Eles levaram meu chinelo e eu tive que ir embora descalço. Eles: "Não, onde vocês roubou esses trem aí?", aí eu falei "É meu, minha mãe comprou"; eles "Não, você roubou no supermercado, eles denunciaram"; falei "Minha mãe comprou"; ele "Fala baixo comigo moleque, senão te desço o tapa"; eu "Não, desculpa"; ele "Então tá. Passa o chinelo" (J.3).

É possível identificar na cena dramatizada a relação de opressão que se estabelece entre a polícia e os jovens de classe baixa. No relato dos jovens durante as oficinas de improvisaçáo teatral, os policiais frequentemente abusam de seu poder para revistar casas, mochilas e eles próprios, mesmo quando inocentes, abordando-os de forma violenta e desrespeitosa. Como se caracteriza uma situação de opressão, o oprimido acaba acatando as determinaçôes do opressor, considerando que este detém o poder, que no caso do policial se materializa na arma e na possibilidade de prender o jovem. Todas essas situaçóes de cenas de vida passaram a ser expressas e discutidas a partir de técnicas como teatro-imagem, dramaturgia simultânea e teatro-fórum, gerando momentos de reflexão e debate no grupo.

O terceiro aspecto observado foi sexualidade, em que os participantes abordaram principalmente o tema gravidez na adolescência, como destacado abaixo.

Professora, lá na escola tinha uma colega minha [...] ela ficou um tempo sem ir e depois ela voltou, ela "tava” grávida. Aí ela pegou e teve que parar de estudar "pra" cuidar do neném (J.5).

De acordo com Aquino et al. (2003), a gravidez na adolescência náo é um fenômeno recente, considerando que mesmo na antiguidade mulheres tinham filhos nesse ciclo vital. Entretanto, para os autores, na atualidade esse tema alcançou maior visibilidade social com um discurso, geralmente, de caráter negativo, sugerindo mudanças radicais na vida dos adolescentes. Dentre essas mudanças os autores apontam o abandono dos estudos e futura dificuldade de encontrar emprego, sendo necessário, no entanto, um olhar ampliado, uma vez que o abandono dos estudos pode ser influenciado por outros motivos e não somente devido à gravidez.

Esse imaginário social se evidencia na fala da participante que traz ao grupo a temática para que possa ser discutida entre os pares através das cenas teatrais improvisadas, revelando a necessidade de suporte para compreensáo dos impactos de uma gravidez na vida de uma jovem.

\subsection{Teatro e microcosmos sociais: o grupo e a família dos jovens}

A segunda categoria, o teatro e os microcosmos sociais do grupo e da família, aborda as formas de interaçáo social observadas a partir dos jogos teatrais e dos relatos dos participantes, bem como a percepção dos mesmos quanto à influência do teatro nas relaçóes interpessoais.

O primeiro aspecto observado relaciona-se aos comportamentos e formas de interação observadas a partir de jogos teatrais. Durante algumas intervençóes foi possível perceber, no comportamento dos jovens, timidez, medo da exposição, dificuldade de tomar iniciativa, brincadeiras violentas, isolamento social, interação social negativa, rejeição do outro, assim como espírito de liderança, euforia e facilidade para o estabelecimento de uma atmosfera lúdica. 
Percebeu-se que tais comportamentos podem ser derivados de características da própria adolescência, assim como também influenciados pelo contexto sociocultural em que esses jovens estão inseridos e, por último, pelos conflitos preexistentes no grupo.

Assim, percebe-se que os jovens, mesmo em um grupo, ainda se subdividiam e utilizavam a exposiçáo negativa e excludente do outro, como uma forma de reafirmar sua identidade em construção. Há de se considerar também a influência do contexto em que estấo inseridos, sendo a violência muitas vezes uma das predominantes formas de expressão, dificultando as relações, como é possível identificar nas falas abaixo.

[Ele] "é chato"; "Não vou conversar com ele náo"; "Tira ele" [do jogo] (J.7, J.2, J.10). Ô gente, por que vocês têm preconceito contra [ele]? (J.9). Eu não tenho preconceito não (J.8).

Notou-se que os jogos teatrais evidenciavam as relaçóes interpessoais e permitiram que os jovens se auto-observassem e refletissem sobre os conflitos preexistentes no grupo, como preconceito e exclusão, gerando diálogos durante e após os jogos. Nesse sentido, Liberman (2002, p. 2) contribui quando traz que a utilização da arte como recurso possibilita o

[...] estabelecimento de vínculos e, ao mesmo tempo, permite a 'materialização' dos conteúdos emocionais, sentimentos e desejos e a efetivação de processos de expressão, conhecimento de si, do outro e do mundo. As vivências no campo das artes contribuem para [...] que o sujeito se perceba como tal, identifique seus diferentes 'modos de funcionamento' para, em seguida, repensá-los e (re)construí-los. (LIBERMAN, 2002, p. 2).

Outro aspecto observado foi a percepção dos jovens sobre o impacto do teatro em suas relaçóes interpessoais cotidianas, tanto no contexto familiar, quanto no contexto do grupo. Os participantes manifestaram que o teatro possibilitou a diminuição da timidez e uma melhora relativa nas relaçóes interpessoais, evidenciando, no entanto, que, embora menos intensos, alguns conflitos ainda persistiam.

Todo mundo ficava me xingando, agora xinga, mas pouco (J.4). Mudou. Eu nem conversava com ele, agora eu converso. Os exercícios que a gente fazia eram muito "bom", "ajudava" muito a aproximar as pessoas (J.9).

Observou-se ainda que a atividade teatral, a partir das discussōes e reflexôes sobre as situaçôes-problemas vivenciadas pelos jovens na comunidade, possibilitou uma abertura de diálogo com a própria família sobre os problemas vivenciados nesta fase da vida, sugerindo a eficácia dessas atividades para o desenvolvimento socioemocional dos jovens.

[O teatro ajudou a] conversar com a família, "fessora". Não conversava nem com meu pai, nem com a minha mãe, eu ficava de boa. Agora eu falo, converso [...] converso o quê que eu acho desses "noiado" aí da rua (J.1).

Nesse sentido, Saraceno (1999) contribui alertando que é necessário que as atividades realizadas pela terapia ocupacional promovam uma construção de sentimento de pertença em relação à comunidade, podendo, por exemplo, modificar os modos de convívio com a família e aumentar a circulação na rede social.

Em consonância, Sullivan et al. (2008) apontam que o teatro do oprimido apresenta efeitos terapêutico a partir da expressão de sentimentos relacionados a situações de opressão. A experimentação de papéis permite a flexibilidade do olhar possibilitando a modificação do comportamento do sujeito, cabendo a ele escolher qual papel protagonizar em sua vida. Considerando esse aspecto, essa metodologia pode ser um instrumento eficaz na mudança das atitudes e crenças desses sujeitos e comunidades em situação de vulnerabilidade (SULLIVAN et al., 2008).

\subsection{Teatro-fórum e elaboração de estratégias de enfrentamento}

$\mathrm{Na}$ terceira categoria, teatro-fórum e elaboração de estratégias de enfrentamento, abordam-se as estratégias de enfrentamento das situaçôes de vulnerabilidade visualizadas a partir da técnica do teatro-fórum realizada no decorrer das intervençóes e no dia da apresentação para a comunidade.

Os participantes da pesquisa, a partir das temáticas levantadas durante as oficinas de teatro, a saber, droga, violência, relações com a polícia, sexualidade e relacionamentos interpessoais, elaboraram uma esquete teatral em que a relação entre opressoroprimido se evidenciava nos relacionamentos dos protagonistas da cena. Essa esquete teatral foi apresentada para os membros da comunidade, para a realização da técnica do teatro-fórum de Augusto Boal, na perspectiva, como elucida Coutinho (2006), de uma aproximação e interação dialógica junto aos membros de determinada comunidade, evidenciando a troca de experiências num aprendizado mútuo que se traduz na materialização cênica do universo cultural dos sujeitos que participam da identificação e solução de problemas mediatizados pela arte. 
O primeiro aspecto observado é constituído de estratégias de enfrentamento visualizadas a partir do teatro. Essas estratégias derivaram dos temas selecionados e apresentados pelos participantes. Durante a apresentação do teatro, o público foi convidado a assistir e parar a cena no momento que considerasse mais importante, para tentar modificar a açáo dos protagonistas da cena, apresentando, em seguida, uma solução para a situação de opressão apresentada. As reflexóes do coletivo apontaram, primeiramente, para a necessidade de retroceder no tempo cênico apresentado pelo protagonista.

Podia ser diferente bem antes, se eles não tivessem ido "pra" esse caminho. Se eles tivessem pensado, estudado e trabalhado, eles iam ter o que eles "queresse" (J.5).

Nesta fala, a jovem expressa a necessidade de ações preventivas anteriores aos problemas que suscitaram a entrada do jovem no mundo das drogas, relacionando, principalmente, a importância de reflexão e escolhas pessoais que o levassem a atividades valorizadas socialmente, como o estudo e o trabalho.

Em relação ao abuso de poder da polícia militar sobre jovens, os espectadores discorrem sobre os direitos das crianças e adolescentes preconizados no Estatuto da Criança e do Adolescente (BRASIL, 1990).

Ele pode pedir documento, verificar se ele é "de menor" e a partir daí ele vai conduzir até a promotoria da juventude e chamar o conselho tutelar [...] ele tem que na realidade precaver, porque você não sabe, se ele for menor infrator ele pode ser tão perigoso quanto. A polícia tem que abordar através do diálogo, de saber por que que "tá" na rua e aí encaminhar "pras" autoridades competentes (E.2).

O papel desses grupos teatrais dentro das comunidades é fortalecido em consideração ao fato de que o trabalho é desenvolvido pelos integrantes da comunidade e não por outros grupos desconhecidos. Suas representaçóes refletem a realidade da comunidade, sendo os acontecimentos, personagens e lugares fundados em fatos concretos (DALL'ORTO, 2008).

Dall'Orto (2008, p. 16) aponta que ao fazer parte de um grupo torna-se mais fácil levantar questionamentos e enfrentar situaçóes que até entâo eram consideradas extremamente difíceis. $\mathrm{O}$ autor ainda afirma que a transformação acontece a partir do momento que os atores-sociais tomam consciência do seu papel dentro da comunidade e da sociedade (DALL'ORTO, 2008, p. 16). Nesse sentido, a preservação dos direitos preconizados no Estatuto da Criança e do Adolescente, bem como aparatos institucionais de preservação destes direitos, foi abordada durante a discussão do teatro-fórum pelos próprios espectadores, auxiliando a comunidade e os próprios jovens, na tomada de consciência destes direitos sociais perante o poder opressor da polícia junto a este público. Materializou-se, nesta experiência, a perspectiva de constituiçáo de um espaço popular em que a comunidade desenvolve formas ativas para enfrentar as dificuldades do dia a dia que adentram os limites sociais de sua existência (COUTINHO, 2006).

Para Sullivan et al. (2008), o teatro-fórum mobiliza a comunidade para buscar melhorar suas condições de vida. Mesmo que não assuma uma ação sustentada, não tenha sucesso, é o ponto de partida para o crescimento de uma consciência crítica por parte dos sujeitos da comunidade, sendo a base para movimentos e açôes futuras.

Outro aspecto observado se relaciona com o teatro como instrumento de conscientização e de estímulo à participação social dos jovens. Aqui são identificados discursos dos espectadores e dos participantes que enfatizam a contribuiçáo do teatro enquanto um recurso para conscientizar e estimular a participação juvenil.

Quando questionados sobre a possibilidade de mudanças na forma de perceberem as problemáticas vivenciadas por eles, retratam que o teatro incentivou a reflexão sobre os temas.

[...] porque antes eu não pensava nisso não "fessora”. Aí, assim, no teatro eu comecei a pensar mais (J.9). Encenando, fazendo gesto, tipo conscientizando que a gente náo deve andar por esse caminho, eu nem vô (J.7). Foi bom "pra" abrir a consciência, se "tá" fazendo alguma coisa, sempre comunicar alguém do que for fazer (J.3).

Freire (1980, p. 26) esclarece que o processo de conscientização necessita que ultrapassemos a esfera espontânea de apreensão da realidade, para chegarmos a uma esfera crítica na qual a realidade se dá como objeto cognoscível e na qual o homem assume uma posição epistemológica. Assim, para o autor, a conscientização náo pode existir fora da práxis - sem o ato ação-reflexão -, o que constitui o modo de ser ou de transformar o mundo.

Tânia Márcia Baraúna Teixeira (2007, p. 85) aponta que para Boal, a função da arte é criar consciência, uma consciência da verdade e do mundo. A autora aponta que o teatro do oprimido busca 
[...] ajudar o espectador a preparar açóes reais que conduzam a própria liberação, pois a liberação do oprimido será obra do próprio oprimido, jamais será outorgada por seu opressor [...] o importante para Boal é que o espectador entre em cena e retome seu direito de protagonizar, transformar as imagens do mundo que lhe são mostradas, para depois poder transformar o próprio mundo. (TEIXEIRA, 2007, p. 86-87).

Nesse sentido, Teixeira (2007) aponta que o teatro é o lugar para ensaio dos atos futuros, atos de libertação. O que se relaciona com a fala destacada abaixo durante o teatro-fórum:

Há alguma coisa que é irreal e você pode transformar isso "pra” realidade, certo? Então eu acho que o teatro é "pra” isso, mostrar o que "tá" errado e mostrar o que "tá" certo. Essa mudança da cena eu achei espetacular, porque você pode mudar o teatro, agora, com uma outra proposta, com outro ato, você vai mudar "pro" real, "pra” realidade (E.2).

Assim, é possível perceber que o teatro se faz importante também para o ensaio de diferentes posturas ativas que podem ser adotadas pelos integrantes da comunidade. Nesse sentido, Teixeira (2007, p. 87) corrobora dizendo que o teatro do oprimido tem o objetivo de desenvolver as capacidades expressivas das pessoas, transformá-lo em criador, oferecendo-lhe simultaneamente o conhecimento de uma linguagem cotidiana e artística. Foi possível identificar que a partir das intervençóes houve uma sensibilização de alguns participantes quanto aos problemas da comunidade, evidenciando o potencial para o incentivo ao protagonismo juvenil e participação social em açóes de solidariedade aos problemas apresentados na comunidade.

Lá no bairro não tem muitas pessoas "que preocupam" com o bairro não (J.5). Mudou um pouco, porque [com] a maioria das pessoas não converso, aí, vou conversar agora. Sobre droga. Assim, o que eu vejo, ajudar mais, sabe, não ficar de fora das coisas "boa". E dar mais conselho "praqueles" assim que quer fumar, porque eu não dava, não falava nada, eu via (J.9).

Teixeira (2007, p. 123) corrobora apontando que

[...] tanto Boal quanto Freire defendem o diálogo e a cooperação entre sujeitos na busca de problematizar, compreender e transformar a realidade.
Nesse sentido, a autora aponta que ambos buscam dar a palavra aos sujeitos, para que eles desenvolvam sua autonomia e se engajem na transformação do mundo. Através do teatro, Boal dá voz ao sujeito, possibilitando que este relate suas vivências, desenvolvendo juízo crítico e responsabilidade, estimulando sua participação social (TEIXEIRA, 2007). De espectadores passivos (“eu via”), os sujeitos passam a atores ativos na transformação da realidade (“aí, vou conversar”, “ajudar mais”).

Nesse aspecto, ao considerar a participação social do sujeito no seio comunitário, a atividade teatral proporciona a possiblidade do jovem se inserir no âmbito da vida coletiva, percebendo-se como um sujeito ativo no processo de mudança do seu ambiente. Essa inserção do jovem a partir da interatividade positiva e solidária com a sua comunidade proporciona maior engajamento social e ampliação da sua rede de suporte, além de promover oportunidades para a garantia de sua participação em atividades significativas podendo gerar, dessa forma, um quadro de justiça ocupacional.

Para Teixeira (2007), o teatro do oprimido possibilita que os sujeitos sociais visualizem mudanças concretas, mesmo que pequenas, num estímulo à mobilização social. Para a autora tal mobilização interfere nas relaçóes sociais, promovendo aprendizagem individual e coletiva. $\mathrm{O}$ teatro do oprimido, como aponta Teixeira (2007, p. 126), deve viabilizar

[...] a promoçáo de mobilizaçáo tanto no plano dos membros atuantes, quanto da plateia, que é estimulada a refletir, opinar e participar ativamente da construção teatral.

O uso do teatro do oprimido possibilita que o terapeuta ocupacional realize o papel proposto por Galheigo (2003, p. 44) de

[...] auxiliar o sujeito, o grupo e a coletividade a compreender suas próprias necessidades e definir suas estratégias de lidar com os conflitos cotidianos, a ressignificar seu fazer e pensar sua ação [...]

Tratando-se, assim, de uma atividade criadora e artística, a essência humana se revela uma vez que "[...] ao produzir projetos artísticos, os sujeitos estão produzindo o mundo, e consequentemente produzindo a si mesmos.” (CASTRO; SAITO; FONSECA, 2007, p. 5). 


\section{Conclusão}

Em consideração ao caráter qualitativo da pesquisa, sendo a amostragem pequena em um estudo de caso, não é possível generalizar os resultados obtidos. Entretanto, a pesquisa oferece subsídios para a elaboração de estratégias de intervenção com os jovens, evidenciando o potencial das atividades expressivas. Ao selecionar o recurso teatral, no entanto, devem-se analisar as demandas da população alvo, a fim de utilizá-lo com o máximo de aproveitamento.

Embora os participantes tenham apresentado uma dificuldade inicial em compreender a função social do teatro, este possibilitou, ao longo do processo, o desenvolvimento de uma reflexão crítica dos jovens acerca dos problemas vivenciados por eles na comunidade, sendo possível abordar temáticas relacionadas com o cotidiano do bairro.

Percebe-se, portanto, que o recurso teatral constitui um importante recurso que potencializa a expressão do jovem sobre sua realidade de vida $\mathrm{e}$ situaçóes de vulnerabilidade, o que evidencia seu valor para os sujeitos dessa faixa etária, e, portanto, sua eficácia para a abordagem terapêutica a partir de ações territoriais na ampliação da rede social de suporte. Nesse sentido, o teatro do oprimido pode ser vislumbrado como técnica eficaz para a promoção da justiça ocupacional, ao considerarmos sua dinâmica expressiva e seu cunho reflexivo que possibilitam o acesso a um conjunto de atividades significativas envolvendo diferentes áreas de desempenho ocupacional como lazer, brincar, educação e, principalmente, a participação social dos sujeitos envolvidos.

O estudo sinaliza que a técnica do teatro do oprimido, juntamente com a perspectiva e metodologia temática freiniana, possibilitou a instrumentalização dos jovens para a promoção de um diálogo com a comunidade, fazendo com que esta percebesse o papel social do teatro no incentivo à produção de reflexóes sobre as necessidades e problemas vivenciados pela juventude e suas soluçóes no âmbito da vida comunitária. Nesse sentido, a intervenção da técnica do teatro-fórum também incentivou o protagonismo social no âmbito comunitário na promoção de um diálogo e discussão coletiva. Foi possível notar que o teatro, assim como as discussóes temáticas acerca das atividades expressivas durante a realização das oficinas, abriu vias de expressão e diálogo com a própria família dos jovens, fortalecendo, também nesse âmbito, a rede de suporte social dos jovens.
Os jogos teatrais promoveram a expressão de conflitos interpessoais preexistentes no grupo e a elaboração destes, havendo uma mudança parcial dessa realidade. Percebe-se a necessidade de maior tempo de intervençáo para que se promova uma reflexão aprofundada sobre esses conflitos e o desenvolvimento de relaçóes interpessoais pautadas no respeito mútuo. Portanto, ao considerarmos a participação social enquanto área de ocupação, os resultados da pesquisa apontam que esta foi atingida tanto no nível das relações de amizade e coleguismo quanto no âmbito da família e na vida comunitária dos sujeitos participantes.

Estudos longitudinais que possibilitem visualizar o impacto das açôes utilizando o recurso teatral para os jovens se caracterizam como novas possibilidades de pesquisa neste campo.

Atividade potencialmente potente como instrumento de transformação social, das situaçóes de opressão, o teatro pode favorecer ações de empoderamento social de sujeitos e comunidades, tornando-os protagonistas de suas histórias individuais e coletivas, afinal, parafraseando Augusto Boal, devemos construir o futuro, em vez de mansamente esperarmos por ele.

\section{Referências}

ABRAMOVAY, M. et al. Juventude, violência e vulnerabilidade social na América Latina: desafios para políticas públicas. Brasília: UNESCO, BID, 2002.

AMERICAN OCCUPATIONAL THERAPY ASSOCIATION - AOTA. Occupational Therapy Practice-Framework: Domain \& Process. American Journal Occupational Therapy, v. 62, n. 9, p. 625-683, 2008. AQUINO, E. M. L. et al. Adolescência e reprodução no Brasil: a heterogeneidade dos perfis sociais. Cadernos de Saúde Pública, Rio de Janeiro, v. 19, p. 377-388, 2003. Suplemento 2.

BARROS, D. D.; LOPES, R. E.; GALHEIGO, S. M. Terapia Ocupacional Social: Concepçóes e Perspectivas. In: CAVALCANTI, A.; GALVÃO, C. Terapia Ocupacional: Fundamentação \& Prática. Rio de Janeiro: Guanabara Koogan, 2007. p. 347-353.

BRASIL. Estatuto da Criança e do Adolescente. 3. ed. Brasília: Editora do Ministério da Saúde, 1990.

BRASIL. Conselho Nacional de Juventude. Política Nacional de Juventude: diretrizes e perspectivas. São Paulo: Conselho Nacional de Juventude; Fundação Friedrich Ebert, 2006.

BOAL, A. Teatro do oprimido e outras poéticas políticas. 9. ed. Rio de Janeiro: Civilização Brasileira, 2009.

BOAL, A. O arco-íris do desejo: o método Boal de teatro e terapia. Rio de Janeiro: Civilização Brasileira, 2002. 
BOAL, A. Jogos para atores e não-atores. 13. ed. Rio de Janeiro: Civilização Brasileira, 2008.

CARleTO, D.; AlveS, H. C.; GONTIJO, D. T. Promoção de Saúde, Desempenho Ocupacional e Vulnerabilidade Social: subsídios para a intervenção de Terapia Ocupacional com adolescentes acolhidas institucionalmente. Revista de Terapia Ocupacional da USP, São Paulo, v. 21, n. 1, p. 89-97, 2010.

CASTRO, M. G. et al. Cultivando vida, desarmando violências: experiências em educação, cultura, lazer, esporte e cidadania com jovens em situação de pobreza. Brasília: UNESCO, 2001.

CASTRO, E. D.; SAITO, C. M.; FONSECA, F. V. D. Os ateliês de corpo e arte em terapia ocupacional: produção de vida e de participação sócio-cultural. In: CONGRESSO BRASILEIRO DE TERAPIA OCUPACIONAL, 10., 2007, Goiânia. Anais... Goiânia: ABRATO, 2007.

CAVALCANTE, B.; STARLING, H.; EISENBERG, J. Decantando a república: inventário histórico e político da canção popular moderna brasileira - a cidade não mora mais em mim. Rio de Janeiro: Nova Fronteira, 2004.

CÔRTES, C.; GONTIJO, D. T.; ALVES, H. C. Açôes da Terapia Ocupacional para a prevenção da violência com adolescentes: relato de pesquisa. Revista de Terapia Ocupacional da USP, São Paulo, v. 22, n. 3, p. 208-215, 2011.

COSTA, A. C. G. Tempo de servir: o protagonismo juvenil passo a passo; um guia para o educador. Belo Horizonte: Universidade, 2001.

COUTINHO, M. H. O uso da abordagem dialógica do teatro em comunidades na experiência do grupo Nós do Morro, da favela Vidigal, no Rio de Janeiro. Interaçóes - Cultura e Comunidade, Rio de Janeiro, v. 1, p. 108-123, 2006.

DAll'ORTO, F. C. O Teatro do Oprimido na Formação da Cidadania. Fênix - Revista de História e Estudos Culturais, [s.1.], v. 5, ano 5, n. 2, p. 1-16, 2008. Disponível em: <http://www.revistafenix.pro.br/PDF15/ Artigo_03_ABRIL-MAIO-JUNHO_2008_Felipe_ Campo_Dall_Orto.pdf>. Acesso em: 04 out. 2010.

FREIRE, P. Conscientizaçâo: teoria e prática da libertação; uma introduçáo ao pensamento de Paulo Freire. 3. ed. São Paulo: Moraes, 1980.

FREIRE, P. Pedagogia do Oprimido. 17. ed. Rio de Janeiro: Paz e Terra, 1987.

FREIRE, P. Pedagogia da Autonomia. Saberes necessários à Prática Educativa. São Paulo: Paz e Terra, 1996.

GALHEIGO, S. M. O social: idas e vindas de um campo de ação em terapia ocupacional. In: PÁDUA, E. M. M.; MAGALHÂES, L. V. Terapia ocupacional, teoria e prática. Campinas: Papirus, 2003. p. 29-48.
LIBERMAN, F. Trabalho corporal, música, teatro e dança em Terapia Ocupacional: clínica e formação. Cadernos - Terapia Ocupacional: Produção de conhecimento e responsabilidade Social, São Paulo, v. 8, n. 3, p. 39-43, 2002.

LOPES, R. E. et al. Juventude Pobre, Violência e Cidadania. Saúde e Sociedade, São Paulo, v. 17, n. 3, p. 63-76, 2008. http://dx.doi.org/10.1590/S0104-12902008000300008

MINAYO, M. C. S.; DESLANDES, S. F.; GOMES, R. Pesquisa Social: teoria, método e criatividade. 25. ed. Petrópolis: Vozes, 2007.

MOREIRA, E. M.; QUEIROZ, T. C. N. Juventude e cultura em comunidades precarizadas: a difícil construção da cidadania. In: ALVIM, R.; QUEIROZ, T.; FERREIRA JÚNIOR, E. Jovens e juventude. João Pessoa: Editora Universitária, PPGS/UFPB, 2005. p. 51-64.

ORGANIZAÇÃO DAS NAÇÓES UNIDAS - ONU. World youth report 2005: young people today, and in 2015. Nova York: Department of Economic and Social Affairs, 2005.

SARACENO, B. Libertando identidades: da reabilitação psicossocial à cidadania possível. Rio de Janeiro: Te Corá, 1999.

SCHENKER, M.; MINAYO, M. C. S. Fatores de risco e de proteção para o uso de drogas na adolescência. Ciências \& Saúde Coletiva, Rio de Janeiro, v. 10, n. 3, p. 707-717, 2005.

SULLIVAN, J. et al. Theatre of the Oppressed and Environmental Justice Communities: A Transformational Therapy for the Body Politic. Journal of Health Psychology, v. 13, n. 2, p. 166-179, 2008. http://dx.doi. org/10.1177/1359105307086710

SPOSITO, M. P.; CARRANO, P. C. R. Juventude e Políticas Públicas no Brasil. Revista Brasileira de Educação, n. 24, p. 16-39, 2003. http://dx.doi.org/10.1590/ S1413-24782003000300003

TAVARES, B. F.; BÉRIA, J. U.; LIMA, M. S. Fatores associados ao uso de drogas entre adolescentes escolares. Revista de Saúde Pública, São Paulo, v. 38, n. 6, p. 787-796, 2004. http://dx.doi.org/10.1590/ S0034-89102004000600006

TEIXEIRA, T. M. B. Dimensóes Sócio Educativas do Teatro do Oprimido: Paulo Freire e Augusto Boal. 2007. 335 f. Tese (Doutorado Educação e Saúde)-Universidade Autônoma de Barcelona, Barcelona, 2007.

TEIXEIRA, R. B. A interface entre a Terapia Ocupacional e o Teatro: de Oprimido a Sujeito. In: CONGRESSO BRASILEIRO DE TERAPIA OCUPACIONAL, 12 ; CONGRESSO LATINO-AMERICANO, 9., 2011, São Paulo. Anais... São Paulo: ABRATO, 2011. 


\section{Contribuição dos Autores}

Izabela Alves desenvolveu a pesquisa e a redação do texto. Daniela Gontijo contribuiu com as reflexôes e revisão do texto. Heliana Alves orientou a pesquisa e a redaçáo do manuscrito. Todas as autoras aprovaram a versão final do texto.

\section{Notas}

${ }^{1}$ Este artigo é resultado de uma pesquisa como parte de requisito para graduação em terapia ocupacional na UFTM e foi aprovado pelo Comitê de Ética em Pesquisa em Seres Humanos da UFTM com o parecer n. 1.570. Parte das reflexóes aqui expostas foi apresentada na II Mostra Científica da Terapia Ocupacional na UFTM e no V Congresso Brasileiro de Ciências Sociais e Humanas em Saúde. 